\title{
The prevalence of the third and fourth heart sounds in clinically healthy Holstein cattle Ali Rezakhani* and Mehdi Zarifi
}

\author{
Address: Department of Clinical Studies, School of Veterinary Medicine, Shiraz University, Shiraz, 71345, Iran \\ Email: Ali Rezakhani* - rezakhania@yahoo.com; Mehdi Zarifi - mzkalyani@gmail.com \\ * Corresponding author
}

Published: I May 2007

Acta Veterinaria Scandinavica 2007, 49:12 doi:10.1186/175I-0147-49-12

This article is available from: http://www.actavetscand.com/content/49/1/12

(C) 2007 Rezakhani and Zarifi; licensee BioMed Central Ltd.

This is an Open Access article distributed under the terms of the Creative Commons Attribution License (http://creativecommons.org/licenses/by/2.0), which permits unrestricted use, distribution, and reproduction in any medium, provided the original work is properly cited.
Received: 3I May 2006

Accepted: I May 2007
Compared to information available on the third and fourth heart sounds in the horse [1] there is a paucity of information on these sounds in cattle in the veterinary literature, although auscultation is the main step in clinical examination of both the cardiovascular system and the animal as a whole. Most literatures describe bovine cardiac sounds and mention that all four heart sounds may be heard in cattle $[2,3]$. A review of veterinary literature failed to find information with regard to the prevalence of the third and fourth heart sounds in clinically healthy cattle. This preliminary study was undertaken to find out the incidence of these sounds in clinically healthy cattle.

Three hundred clinically healthy Holstein cattle from 12 dairy farms in Shiraz area were chosen randomly for population to be studied. About 10 minutes after restraining the animals in a stock, the cardiac area was auscultated by two clinicians independently and systematically by a Littman type stethoscope without consulting with each other and then both clinicians listened the heart sounds simultaneously using a sensor stethoscope (Mediron stethoscopes AS, Norway) focusing on the transient heart sounds and cardiac murmurs according to criteria have been presented $[4,5]$. Before auscultation both sides of cardiac area was palpated for the detection of apex beat. Then stethoscope was placed on the area of the thorax in which apex beat was most clear and attention was focused on the first and second heart sounds and then the stethoscope was moved to the mitral, aortic, pulmonary and tricuspid valves area. The right side of the cardiac area was also auscultated. The age, hear rate and clinical signs of heart disease such as jugular distention and pulsation, edema and thrill were taken into consideration. Animals with the signs of heart diseases were not included in this study.

The results of this study showed that the third heart sound was audible in $8.7 \%$ of animals and $29.3 \%$ demonstrated the fourth heart sound (Table 1). The prevalence of the fourth heart sound was significantly higher in cattle older than 48 months. None of the calves younger than twelve months had the third heart sound. Both sounds were more prevalent in older ages. There was a reverse correlation between the heart rate and the $4^{\text {th }}$ heart sound. The higher the heart rate the less chance was to hear the $4^{\text {th }}$ heart sounds. The percentage of audible fourth heart sound in the heart rate of higher and lower than 100 BPM was $10.3 \%$ and $36 \%$ respectively, which was statistically significant $(\mathrm{F}=18,5, \mathrm{df}=1, \mathrm{P}=0.000)$.

'It has been mentioned that the $3^{\text {rd }}$ heart sound can be heard when heart rate increases $[6,2]$. We could not confirm this finding in our study as the $3^{\text {rd }}$ and $4^{\text {th }}$ heart sounds disappeared as soon as the heart rate accelerated. The majority of the third heart sound had maximal point of intensity over the ventral part of the cardiac area where the first heart sound is clearly audible. The fourth heart sound was audible on the base of the heart

It seems that audibility of the third and fourth heart sounds is partly related to the heart rate. In animals with higher heart rate such as dogs, goats, sheep and pigs, these sounds are not heard and only the first and second heart sounds are audible in these animals. On the other hand these sounds, specially the fourth heart sound, are auscultated easily in over $60 \%$ of fit horses [7] because the heart 
Table I: The mean heart rate and prevalence of third and fourth heart sounds

\begin{tabular}{llll}
\hline Age groups (month) & The mean of HR (mean \pm SE) & S3 (\%) & S4 (\%) \\
\hline $1-12(n=55)$ & $115.36 \pm 2.18^{\mathrm{a}}$ & $0 \mathrm{a}$ & $3.6^{\mathrm{a}}$ \\
$13-24(\mathrm{n}=42)$ & $99.88 \pm 2.63^{\mathrm{b}}$ & $2.4^{\mathrm{a}}$ & $4.8^{\mathrm{a}}$ \\
$25-48(\mathrm{n}=98)$ & $84.39 \pm 2.05^{\mathrm{c}}$ & $18.4^{\mathrm{b}}$ & $37.8^{\mathrm{b}}$ \\
$>48(\mathrm{n}=105)$ & $81.52 \pm 1.66^{\mathrm{c}}$ & $6.7^{\mathrm{a}}$ & $44.8^{\mathrm{b}}$ \\
\hline Total $(\mathrm{n}=300)$ & $91.23 \pm 2.18$ & 8.7 & 29.3 \\
\hline
\end{tabular}

Values in the same column followed by a different letter indicate a significant difference $(P<0.05) H R=$ Heart rate, $S 3=$ third heart sound, $S 4=$ fourth heart sound

rate is lower in this species of animal and the P-R interval is longer than cattle so the fourth heart sound is separated from the first heart sound. In cattle the heart rate $(75.73 \pm$ 9.13) [8] is higher than the horse and lower than dogs, goats, sheep and pigs so it is possible to hear these two sounds in some clinically normal cattle [6]. However, care must be taken to differentiate these sounds and the splitting of the first and second heart sounds. One of the criteria used in this study to differentiate the third heart sound from splitting of the second heart sound was the effect of high heart rate on the third heart sound. Splitting of the second heart sound usually remains unchanged when heart rate increases.

In conclusion this preliminary study showed that the $3^{\text {rd }}$ and $4^{\text {th }}$ heart sounds can be audible in some clinically healthy cattle so they should be considered normal when there is no clinical sign of heart disease.

\section{References}

I. Patteson MW, Cripps PJ: A survey of cardiac auscultatory findings in horses. Equine Vet $\int$ 1993, 25:409-41.

2. Radostits OM, Gay CC, Blood DC, Hinchcliff KW: Veterinary Medicine 9 th edition. London, W. B. Saunders; 2000.

3. Gay CC, Radostits OM: Clinical Examination of the Cardiovascular System. In Veterinary Clinical Examination and Diagnosis Edited by: Radostits OM, Mayhew IG, Houston DM. London: W. B. Saunders; 2000:245-29l.

4. Jackson PGG, Cockcroft PD: Clinical Examination of Farm Animals Oxford: Blackwell Science; 2002:5 I-64.

5. Bonagura JD, Reef VB: Diseases of the Cardiovascular System. In Equine Internnal Medicine Edited by: Reed SM, Bayly WM, Sellon DC. St. Louis: W. B. Saunders; 2004:355-459.

6. Callan RJ, McGuirk SM, Step DL: Assesment of the cardiovascular system. Vet Clin North Amer (Food Anim) 1992, 8:257-270.

7. Reef VB: Evaluation of equine cardiovascular system. Vet Clin North Amer(Equine Pract) 1985, I:275-280.

8. Rezakhani A, Papahn AA, Shekarfroush S: Analysis of base apex lead electrocardiograms of normal dairy cow. Vet Arhiv 2004, 74:35I-35.

\section{Publish with Biomed Central and every scientist can read your work free of charge}

"BioMed Central will be the most significant development for disseminating the results of biomedical research in our lifetime. "

Sir Paul Nurse, Cancer Research UK

Your research papers will be:

- available free of charge to the entire biomedical community

- peer reviewed and published immediately upon acceptance

- cited in PubMed and archived on PubMed Central

- yours - you keep the copyright

Submit your manuscript here:

http://www.biomedcentral.com/info/publishing_adv.asp
BioMedcentral 